\title{
Language Skills Development: Developing Speaking Skills at Undergraduate Level using a Smart Phone - Practical Observations
}

\author{
Dr. K. V. Madhavi \\ Assistant Professor of English, GITAM University, Hyderabad
}

\begin{abstract}
Speaking is often neglected in a classroom situation. The present day competitive world requires communicative competency to achieve progress in professional career. According to Brown and Yule (1983), speaking is the skill that the students will be judged upon most in real-life situations. Speaking carries the first impression of a person. Today technology has paved a way to achieve academic success in an effective way. A classroom is no longer identified by a teacher, black board and a chalk. The availability of computers, laptops, internet, video conferencing, smart phones, tablets, $i$ phones, $i$ pads etc. has changed the teaching and learning process in a classroom. The present paper focused its attention on enhancing speaking skills using smart phones in real time situations and conducting various activities like group discussions, paper presentations, role plays, etc. The main focus is on identifying the learner's level and conducting a learner centric approach for the improvement of speaking skills.
\end{abstract}

Keywords: Teaching Language Skills, Speaking Skills, Undergraduate Level, Smart Phone, Practical Observations

\section{Introduction}

Speaking is often neglected in a classroom situation. The present day competitive world requires communicative competency to achieve progress in professional career. Speaking carries the first impression of a person. According to Osborn, "effective speaking skills result in achievements during ceremonial speaking activities, job training activities, job interviews, and many other business purposes." Zaremba (2006) also pointed out a study indicating that speaking skills or communication skills were usually placed ahead of work experience, motivation, and academic credentials as criteria for new recruitment for employment.

However, the students are unable to develop speaking skills. According to Trent, "One among many reasons to take into consideration might be a lack of confidence in terms of anxiety about making errors." To strengthen the speaking skills among the learners, the present paper focussed its attention on the first year engineering graduates who have a very limited exposure to speaking activities either in their schooling or at intermediate level. As Tam suggested, "Providing students with a variety of situations, confidence and competence usually lead to strengths of English speaking skills," different activities are planned as a part of their curriculum. Patil (2008) asserted that building up the learner's confidence to eliminate fear of making errors was a priority that the teacher should consider in order to make the learner feel comfortable with their language use.

There are some categories that can be used as the role of learners in developing speaking skills in the classroom (Brown, 1994):

- Intensive - It goes one step beyond imitative to include any speaking performances that are designed to practice some phonological or grammatical aspects of language.

- Responsive - It consists of short replies to teacher-or student-initiated questions or comments.
- Transactional (dialogue) - Transactional language, carried out for the purposes of conveying or exchanging specific information is an extended form of responsive language.

- Interpersonal (dialogue) - It carried out more the purpose of maintaining social relationships than for the transmission of a fact and information. These conversations are little trickier for learners because they can involve some or all of the following factors - a casual register, colloquial language, emotionally charged language, slang and sarcasm.

- Extensive (monolog) - Here the register is more formal and deliberative. It can be planned or impromptu.

\section{Methodology Adopted}

The researcher adopted the method of identifying various activities like introducing one self, team presentations, individual PPT presentations, Group Discussions as a part of assessing the learners speaking skills. The assessment is analyzed and interpreted in the form of a pre test and a post test.

\section{The Sample Learners}

The sample learners completed their intermediate or +2 level. Every batch consists of 30 students. A negligible number ( 1 or 2 students) from each batch are from +2 level (CBSE/ICSE syllabus who were exposed to different speaking activities like Just A Minute, Group Discussions, Presentations etc). The remaining students are not exposed to English language learning during their intermediate. The English subject was taught for 1 - 2 months in order to complete the syllabus and printed material was supplied along with the question bank. A majority of the students by heart the subject and negligible exposure to grammar and vocabulary building is found. 


\section{International Journal of Science and Research (IJSR) \\ ISSN (Online): 2319-7064}

Index Copernicus Value (2013): 6.14 | Impact Factor (2014): 5.611

For effectiveness of speaking, Shumin (1997) pointed out a number of elements involved, including listening skills, socio cultural factors, affective factors, and other linguistic and sociolinguistic competence such as grammatical, discourse, sociolinguistic, and strategic competence. The researcher used multimedia resources and class room teaching for improving LSRW Skills, pronunciation, grammar and vocabulary skills.

Communication Skills Lab: The researcher used Communication Skills Lab that is equipped with group discussion tables, seating chairs, Computer, and LCD for conducting Pre Test and Post Test.

Use of Multimedia Language Lab: After the pre test, the learners were exposed to multimedia language lab. Different software like Learn to Speak English, Pronunciation Power 2, and Study Skills Success etc. are being used in the lab. Online resources and different videos on Speaking Skills are incorporated along with the teacher inputs.

Use of Smart Phone: The researcher used the smart phone during the pre test and post test. The smart phone is easy to carry and has the potential to store data. The availability of high quality multimedia storage capacity using internal or removable memory cards helped to record, review, store or remove the data. The battery is long lasting. In the absence of PA system, computer, or any operating system, smart phone helps to record the data and the learners can access the data instantly or copy it in the DVD's and review the performance. Using video conferencing tools, the data can be communicated and feedback is given at any point of time and the progress can be tracked.

A smart Phone was used to record all the speaking activities during the pre test and the post test. The data was transferred to DVD's and the learners were exposed to watching their own and other participant's videos for quick, instant and immediate feedback. The progress was tracked along with various inputs, suggestions from the researcher and also from the participants.

The Pre Test: The students were exposed to various speaking activities. Every batch was allotted 3 hours per week. The activities included:

1) Self Introduction: The following parameters were considered:

a) Content: A majority of the students presented their introduction that matches the school level. It filled with their and parents name, parent's occupation, hobbies like watching TV, playing cricket etc.

b) Eye Contact: A majority of the students lacked eye contact. They either looked at the teacher, roof or one or two listeners.

c) Body Language: A majority of the students could not maintain appropriate body language. The learners stood on one leg, lean forward, either move vigorously or maintain static movement, fold hands at their back or front, no proper gestures, and facial expressions.

d) Appearance: A majority of the learners wear informal attire like $\mathrm{T}$ shirts, faded jeans with no proper colour combination; untidy hair style; no formal shoes or sandals etc. e) Delivery: A majority of the students maintained feeble voice. The pace and speed of the content was either too fast or slow. Fillers like umhs, uhs, too many pauses were observed.

\section{2) Presentation Skills:}

a) Pair work: The sample learners were randomly selected to form a pair and various situations related to informal conversations and formal conversations were given. All the learners should prepare their dialogues and enact in front of the audience. A majority of the learners presented their dialogues in the form of reading. No facial expressions, proper body language, and proper eye contact. The language skills were extremely poor in formal contexts.

b) Team work: The sample learners were randomly selected to form a team of four members. The researcher randomly selected some newspaper or magazine articles and allotted the task of presenting the chosen topic. A majority of the learners were found with no proper planning, preparation and presentation. The students divided the articles into four parts and read the same .Some could not even open their mouth. There was no team coordination.

c) Individual PPT presentation: A majority of the sample learners downloaded the PPT's from internet. It is observed that the presentation skills are extremely poor. A majority of the learners were hesitant to present before the audience and many absented themselves for the lab sessions.

\section{3) Group Discussion}

a) Initiative: A majority of the members wait for the others to speak. The researcher had to encourage the initiator to start the discussion.

b) Team work: A majority of the participants seemed like giving their points and remained quiet. There was no proper discussion. In almost every team of 6 members, 2 - 3 members spoke and others maintained silence.

c) Eye contact: A majority of the participants didn't look at their team members. The points were presented to the adjudicator.

d) Content: The most popular and current topics were randomly selected and given to each group. However, it is found that a majority of participants lacked knowledge and did not keep abreast with the current happenings. Most of the discussions ended in 3-4 minutes. The points were written in the note book and read without any proper examples, or statistics to enhance the discussion.

e) Body language: A majority of the participants leaned on the table, hands folded, or played with implements like pen, pencil, mobile, etc.

Post Test: After the exposure to multi media and communication skills lab, different English language learning software, internet resources, u tube videos, online material, classroom instruction, teacher inputs, the learners were exposed to post test and speaking activities were conducted to identify the level of improvement.

1) Self introduction: The following parameters were considered: 


\section{International Journal of Science and Research (IJSR) \\ ISSN (Online): 2319-7064}

Index Copernicus Value (2013): 6.14 | Impact Factor (2014): 5.611

a) Content: The participants focused on their qualifications, academic achievements, goals, career objectives, co curricular activities, strengths and weakness etc. They tried to showcase their academic talents and attempted to be different from other participants.

b) Eye Contact: The participants maintained eye contact with the audience. A smile with some humour was also observed.

c) Body Language: A majority of the students could maintain appropriate body language. The learners tried to use the available space; manageable gestures, postures and facial expressions were observed.

d) Appearance: A majority of the learners wore formal attire for the English language lab sessions. Boys wore shirts and trousers with light colours; professional shoe; and tidy hair; shaven beard and neat appearance. Girls maintained professional attire with trimmed nails, tidy hair and neat appearance.

e) Delivery: A majority of the participants maintained audible voice reducing the fillers. The pace and speed of the delivery was improved.

\section{2) Presentation Skills:}

a) Pair work: The sample learners were randomly selected to form a pair and various situations related to informal conversations and formal conversations were given. All the learners prepared their dialogues and enacted in front of the audience. A majority of the learners maintained good dialogue delivery with proper facial expressions, body language, and eye contact. The language skills were worked out and use of appropriate vocabulary in formal contexts was observed.

b) Individual PPT presentation: All the learners prepared their individual PPT's choosing interesting topics. A majority of the learners worked on various planning, preparation and presentation techniques. All the participants were present and those who lacked confidence and presentation style (6-8 students per batch) requested the researcher for another opportunity.

\section{3) Group Discussion:}

a) Initiative: A majority of the participants tried to initiate the discussion.

b) Team work: Every participant tried to speak and if non speakers were found, they were encouraged by the team members to express their opinions.

c) Eye contact: All the participants maintained eye contact. The points were discussed among themselves.

d) Content: The most popular and current topics were randomly selected and given to each group. It was found that a majority of participants tried to keep abreast with the current happenings. The discussions went for $10-12$ minutes with relevant examples and authentic data. In some cases, the adjudicator had to stop the discussion. There was a tremendous improvement in the learners.

e) Body language: Proper posture, explanatory gestures, with appropriate facial expressions were observed.

\section{Conclusion}

Pre Test Observation: Based on the analysis of various speaking activities,
1) A majority of the learners were found with no proper exposure to speaking activities.

2) A majority of the learners lacked confidence and displayed nervousness and stage fear.

3) Different parameters like content, body language, mode of delivery, presentation techniques, appearance, etc. were at the foundation level.

4) Appropriate use of language, grammar, vocabulary, fluency, accuracy etc. was neglected.

Post Test Observations:

1) A majority of the learners were found to enjoy various speaking activities that also developed individual interaction along with pair and team work.

2) A majority of the learners improved their confidence levels.

3) Tremendous improvement in different parameters like content, body language, mode of delivery, presentation techniques, appearance, etc. was found.

4) Appropriate use of language, grammar, vocabulary, fluency, accuracy etc. was improved.

5) A majority of the learners enjoyed themselves viewing their videos, identifying their mistakes and improving their speaking skills.

6) Instant feedback and reviews helped them identify their faults and cope with the demanding situations.

\section{References}

[1] Brown, G. \& G. Yule. (1983a). Discourse Analysis. Cambridge University Press.

[2] Brown, H.D. (1994). Teaching by principles: An interactive Approach to Language Pedagogy. Englewood Cliffs, NJ: Prentice Hall Renents

[3] Osborn, S., Osborn, M., \& Osborn, R. (2008). Public speaking guidebook. Boston: Pearson. Patil, Z.N. (2008). Rethinking the objectives of teaching English in Asia. Asian EFL Journal.10 (4), 227-240. Retrieved from http://www.asianefl-journal.com/December 08 zn.php

[4] Patil, Z.N. (2008). Rethinking the objectives of teaching English in Asia. Asian EFL Journal.10 (4), 227-240. Retrieved from http://www.asian-efljournal.com/December_08_zn.php

[5] Tam, M. (1997). Building fluency: a course for nonnative speakers of English. English Teaching Forum, 35(1), 26. $\quad$ Retrieved from http://eca.state.gov/forum/vols/vol35/no1/p26.html

[6] Trent, J. (2009). Enhancing oral participation across the curriculum: Some lessons from the EAP classroom. Asian EFL Journal, 11(1), 256-270. Retrieved from http://www.asian-efljournal.com/March_09-jt.php

[7] Zaremba, A. J. (2006). Speaking professionally. Canada: Thompson South-Western. 